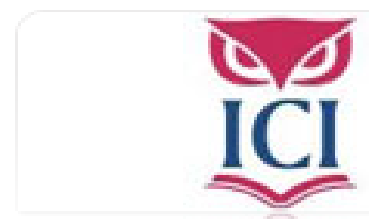

IUS. Revista del Instituto de Ciencias Jurídicas de Puebla A.C.

ISSN: 1870-2147

revista.ius@hotmail.com

Instituto de Ciencias Jurídicas de Puebla A. C.

México

Mendoza Tablero, José Luis

La reforma electoral, coyuntura larga y decisiones de momento

IUS. Revista del Instituto de Ciencias Jurídicas de Puebla A.C., núm. 20, 2007, pp. 306-312 Instituto de Ciencias Jurídicas de Puebla A. C.

Puebla, México 
ca un sistema en el que los poderes piensan más en sus disputas que en representar a los intereses sociales.

Francamente, creo que si no es sobre estas bases las reformas electorales que se postulan por algunos sectores y en algunos países en Latinoamérica son más de lo mismo.

\section{La reforma electoral, coyuntura larga y decisiones de momento}

José Luis Mendoza Tablero

México necesita enfrentar sus problemas y las leyes electorales son parte de ese proceso, si bien se requiere actuar en el marco institucional, para lo cual es preciso una visión de país compartida por una mayoría.

\section{El SISTEMA POLítICO MEXICANO}

Estamos en la salida de un proceso coyuntural electoral en nuestro país. Desde la instauración de la clase revolucionaria hasta 1988 parecía que el ámbito electoral no tenía mayor cambio: la ley de 1946 era el reflejo del centralismo y el poder del presidente; la reforma de 1963, una "zanahoria" para la oposición; la elección de 1976 mostraba que algo estaba pasando, pero se podía solucionar con los diputados de representación proporcional; nada ponía en peligro al partido hegemó- nico. Pero al llegar a 1988 las cosas cambiaron, porque se ponía en tela de juicio toda una serie de tabúes: la elección es un ritual; quien se va del partido oficial, se va de la política; la población en su mayoría no discute los resultados de las elecciones.

\section{Coyuntura electoral 1988-2006}

Pareciera que esta coyuntura empieza en 1988 y termina en el 2006... Muy larga, pero así han sido muchos procesos en México.

A partir de 1988 suceden cosas increíbles: en ese año llegan los primeros senadores de la oposición, por cierto, del Frente Democrático Nacional; el pan (Partido Acción Nacional) gana Baja California en 1989; se crea el IFE (Instituto Federal Electoral) y organiza las elecciones de 1991; el PAN crece de forma por demás espectacular y gana gran cantidad de puestos de elección, incluyendo gubernaturas y escaños para 1994; se fortalece al IFE y se consolida el Tribunal Electoral del Poder Judicial de la Federación (TEPJF, antes tRIFE) en 1996; un año después el PRD (Partido de la Revolución Democrática) gana la Jefatura de Gobierno del Distrito Federal que por primera vez se disputa y logra una mayoría por demás importante en delegaciones y diputaciones locales; además marca el inicio de victorias en las entidades federativas para ese partido; el PRI (Partido Revolucionario Institucio- 
nal) pierde el control de la Cámara de Diputados, con lo cual se inicia un proceso por demás complicado de gobierno dividido, el cual continúa hasta la fecha.

Los procesos descritos continúan y en el 2000 llega el cambio de partido en el Ejecutivo federal, ahora el concepto de oposición empezará a ser más difícil de utilizar; a partir de ahí la alternancia en los ámbitos locales y municipales se hace común, el PRD en 2003 logra una excelente posición en la Cámara de Diputados. Todo lo anterior en un marco de cambios que distan mucho de ser tersos y ordenados, pareciera que afecta el poder del presidente, pero la falta de instituciones democráticas hace que se generen vacíos de poder a los que muchos aspiran.

A pesar de todo, el balance no puede ser negativo, porque ha implicado un proceso que México necesita asumir.

Considero que este proceso coyuntural termina en el 2006, porque mostró que con los cambios planteados se podía llegar a una elección presidencial y cargar con las presiones lógicas de una oportunidad en donde desde la perspectiva del sistema político mexicano, se trata de una elección de suma cero y para agravarlo: el ganador se lo lleva todo.

Me parece que tal como se dieron las cosas, no era el escenario más deseado $;^{1}$ sin embargo, tuvo un

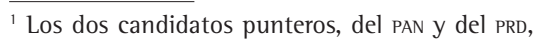

valor que hay que destacar: la sociedad, los partidos políticos y las instituciones soportaron la prueba; aunque se puso en evidencia al IFE, una de las instituciones con mayor fuerza del país: la elección mostró lo mejor del repertorio de la suciedad partidista, las televisoras ejercieron un poder inmenso, al final el sabor de boca fue amargo; en general, los partidos le quedan a deber a la sociedad; lo anterior en un marco en el cual ésta sabía que había que buscar la estabilidad por el bien de la mayoría, aunque eso magnificara las ganancias de unos y aplastara las aspiraciones de otros. El sistema electoral tiene mucho por avanzar, pero no es ni la sombra de lo que fue hace algunas décadas.

\section{Oportunidades y costos DE LA COYUNTURA}

En este periodo 1988-2006 se quiebra con el partido hegemónico, lo cual nos lleva a un sistema de pluralismo moderado, en una cons-

terminaron con una elección cerrada que se decidió por alrededor de medio punto porcentual. El candidato perdedor del PRD desconoce la elección y al IFE, lleva su asunto al TEPJF, del cual tampoco confiaba, pide el recuento total de la elección: "voto por voto, casilla por casilla". Al perder el recurso jurídico como última instancia se asume como "presidente legítimo" y llama a su oponente "espurio". Se genera un movimiento de resistencia con mayor fuerza en el Distrito Federal, que por momentos divide a la sociedad. Poco a poco se baja la intensidad y finalmente no tiene la fuerza para poner en peligro la permanencia del presidente electo. 
tante de alternancia en diferentes niveles. Es importante dar su valor a un periodo como el descrito, porque involucra cierta fuerza y aspiraciones sociales; las coyunturas deben aprovecharse, de otra manera se asumen los costos y no reditúan las oportunidades.

En México parece ser que el resultado fue intermedio, pero al mismo tiempo gran parte de lo que se debió cambiar continúa entre nosotros: relaciones autoritarias y clientelares, planeación inadecuada en la administración pública, falta de visión de país, deficiencias y corrupción en la impartición y procuración de justicia; una vez más para lo que nos ocupa, requerimos de partidos que respondan a la sociedad, mientras nos movemos en la teledemocracia y los partidos "atrapa todo"... la coyuntura acabó y ahora las reglas maduran su vigencia: no somos lo que deseamos (electoralmente hablando), pero hay pasos dados que no admiten regreso.

\section{Para una reforma electoral}

Pasando a la situación actual del panorama electoral, para llegar concretamente al IFE y a la reforma constitucional que tanto ha dado que hablar, hay que decir que la conformación actual de sus miembros en el Consejo General no está cerca de lo aceptable, si bien parece que precisamente eso muestra su fortaleza institucional; éste se ha mostrado como garante de las elecciones federales nada más (y nada menos). Podemos alegar un sinfín de cosas sobre sus yerros, pero creo que los principales responsables son los partidos políticos. Lo cierto es que ahora se cuenta con una gran cantidad de elementos para las elecciones federales que si bien no protegen contra muchas prácticas electorales desleales, representan más que una base de que las elecciones tendrán reglas mínimas adecuadas. Que se cometen excesos, sin duda. Muestra es precisamente de la necesidad de la reforma electoral a la que se le dedica este comentario.

\section{El cambio de los consejeros}

La parte que me parece más delicada de la reforma, es percibir que los partidos políticos quieran cambiar a los consejeros del IFE, basados en que paguen por el resultado de las elecciones presidenciales del 2006 o porque su cabeza tiene precio y está bien pagada... Es un pragmatismo terrible.

La esencia del problema es que los consejeros tenían garantías legales de estar en su cargo hasta el 2010. No pretendo, ni quiero, entrar a su defensa; sin embargo, los diputados (los partidos) los eligieron y no puede ser que ahora ya no les convenzan y entonces se cambie a los consejeros sin respetar las leyes que los propios legisladores de los partidos políticos decretaron. ¿Qué 
pasará si los "nuevos" tampoco satisfacen sus pretensiones?

Ése es el asunto principal: de legalidad. La mejor forma hubiese sido dejar que terminaran sus periodos y entonces iniciar con un sistema escalonado, respetando las normas, y por qué no decirlo: las formas políticas. Porque aun considerando que lo que se quiere hacer sea por el bien de la mayoría, como lo dijera Jesús Reyes Heroles: "en política forma es fondo".

En el caso mexicano tenemos el ejemplo de cuando en 1994 se reforma un requisito para ser presidente, pero la disposición entra en vigor hasta la siguiente elección presidencial, con lo cual se evita que lleve dedicatoria (algunos pensaban en Jaime Serra Puche y está más que claro que éste no se benefició de la modificación). Ahora la reforma dice: "Con cariño para Ugalde y otros”. Las leyes deben ser impersonales bajo pena de no ser efectivas para el problema que plantean.

Insisto: se pudieron hacer todas las modificaciones sin cambiar a los consejeros antes de que concluyera su periodo.

Hay cosas interesantes en la reforma planteada, pero no están inscritas en un marco general del Estado al que los mexicanos aspiramos. Pareciera que caemos en lo de tantas veces: trabajar sobre los aspectos del momento. No veo que se tenga rumbo a mediano plazo, aunque sería excelente que el poder legislativo federal nos explicara en su proyecto de país, por lo menos en lo concerniente a lo electoral, en dónde ubicar a las reformas aprobadas.

De otra manera sólo le servirá a nuestros políticos para "jalar" una bocanada de aire y nos estén mencionando mil veces que gracias a su preocupación y sensibilidad hacen lo que la sociedad demanda, lo cual tiene su parte de verdad, pero me parece que principalmente las reformas son para ayudarse ellos mismos y justificarse, si bien para nadie es desconocido que no precisamente gozan de mucha credibilidad.

\section{Medios Y TELEVISORAS}

Las televisoras (de canales abiertos principalmente) desde hace un tiempo han mostrado que su poder e intereses son grandes. Las vemos ahora mostrarse críticas ante el gobierno y los partidos políticos, cuando fueron tan complacientes. Ahora resulta que hasta preocupadas por la libertad de expresión están, cuando cualquiera se puede dar cuenta de cómo alientan voces o las callan, dedican minutos o segundos (o ni eso) dependiendo de sus intereses; la parte informativa la confunden con sus opiniones.

Los medios masivos de comunicación son sumamente importantes en las elecciones, lo anterior puede o no gustar, pero es un hecho; además el tema se carga en la televi- 
sión, pues la población en general forma su opinión con spots, coberturas, frases, etcétera.

La mayor parte del dinero que destinan los partidos a las campañas se va a la televisión, por eso tiene plena justificación la prohibición a éstos para comprar tiempos en ese medio, ajustándose a lo asignado por el IFE. Pareciera que la borrachera a "tragos" de 20 segundos produjo una "cruda" que se trata de curar en medio de la culpa, pero hay un sentimiento de venganza en contra del "cantinero". Si algo sabemos, es que el adicto se arrepiente aunque mantiene sus necesidades.

\section{Cambios y rumbo en el sistema ELECTORAL}

Lo que tendría que analizarse como parte de las modificaciones necesarias, que es difícil que los partidos políticos las discutan, por afectar muchos intereses, sería:

La representación proporcional. Habría que analizar la conveniencia de la representación proporcional, pues resulta que la población prácticamente desconoce cómo se elige a los diputados plurinominales. El reverso de la boleta parecen las cláusulas de un formato de contrato bancario: nadie las lee... pero son importantes. ${ }^{2}$ La gran pregunta es:

${ }^{2}$ Hay que considerar que 200 de los 500 diputados federales son electos por la vía de la representación proporcional. No es menor el asunto: tienen el 40\% de la Cámara de Diputados. ¿a quién representan y a quién le rinden cuentas? Para acabar pronto: ¿para qué sirven? Si alguien me dice que para representar a las minorías, será para las minorías de las élites, porque no creo que por falta del Partido del Trabajo los obreros se sintieran desprotegidos o que ante la falta del PVEm los ecologistas lamentaran que su voz se ha perdido en el Congreso. Me parece que México ahora necesita de responsabilidades y responsables, eso se puede mostrar mejor con la representación por mayoría relativa.

La reelección. Es difícil avanzar sobre mitos y, cuando se habla de este tema, la clase política tiene en el imaginario a Benito Juárez, Sebastián Lerdo de Tejada, y por supuesto a Porfirio Díaz y principalmente a Álvaro Obregón; en el ámbito legislativo no se tienen tantas reticencias, pero es importante analizar la situación en todos niveles en los dos poderes electos. Me parece que sería positiva, sólo que quizá habría que considerar el periodo para presidente de la República, que es muy largo; el único caso paralelo en América es Chile. Se podría reducir el periodo a cuatro años, ${ }^{3}$ el cual podría ser igual para los diputados, a quienes se podría elegir de manera escalonada por

${ }^{3}$ Con posibilidad de reelección, esto haría que el presidente tuviera un incentivo para hacer su trabajo, además de darle cierto control a la sociedad ante la necesidad de cambiar al Ejecutivo en periodos más cortos. 
mitades, y para el Senado cambios por tercios (igual con posibilidades de reelección), así tendríamos elecciones federales cada dos años. Este sistema electoral se ha puesto en funcionamiento en Argentina y ha mostrado ser viable, sobre todo en la parte escalonada, que proporciona continuidad en el trabajo legislativo.

La relación Ejecutivo-Legislati$v o$. Se requieren mecanismos de comunicación entre estos dos poderes. Uno adecuado sería un Jefe de Gabinete ratificado por el Legislativo, con responsabilidad ante éste, para que por su medio se canalizaran las iniciativas del Ejecutivo. Se podría tener un interlocutor válido para ambas partes y de ahí avanzar sobre la parálisis característica del gobierno dividido.

Los salarios de los legisladores. Algo que simple y sencillamente es insalvable es que los legisladores federales (y no sólo ellos) carecen de autoridad moral para presentarse ante la ciudadanía: nadie puede creer que desempeñen su labor pensando en el bien del país, contando con salarios y compensaciones que no corresponden a la realidad de éste. La idea de disminuir significativamente su sueldo no tiene que ver con la idea de solucionar problemas económicos, sino en proporcionar un poco de dignidad al cargo y atemperar la llegada de personas movidas sólo por la retribución económica.
Las sesiones. Los dos periodos de sesiones en el poder legislativo se podrían cambiar a una sola que inicie en febrero y termine en noviembre, a fin de que se cuente con mayor tiempo para desahogar el rezago legislativo que se tiene; de la misma manera se podría utilizar una regla en el sentido de que no se termina el periodo hasta que se dictamine y vote la última iniciativa recibida en el año.

Como se puede observar, los problemas planteados tienen muchas aristas, pero es necesario definir qué es lo que se quiere hacer con el sistema electoral y considerar sus implicaciones en los poderes electos.

Respecto al rumbo, debemos pensar en un sistema electoral que privilegie la autoridad de los órganos electorales, en donde la mayor parte de los acuerdos y conflictos se resuelvan en el IFE, que representa el nivel "político", por encima de la instancia jurisdiccional (el TEPJF), que debe ser considerada como excepcional, porque de otra manera se desgastan los partidos, las instituciones y se harta la sociedad al percibir que no se pueden acatar las formas políticas.

Los partidos políticos tienen que autolimitarse, como ahora lo intentan, pero no como algo momentáneo, sino entendiendo que al limitarse todos, tienen mejores elementos de independencia frente a los "patrocinadores" y mejor desempeño ante los ciudadanos.

Volver al Índice >> 
Cuesta trabajo creer que los partidos políticos quieran respetarse apelando a la moralidad; sin embargo, existen ventajas para ellos: de otra manera se gana una elección a corto plazo, pero todos terminan con la "cara sucia" y eso en varios ciclos nos da una situación como la actual.

Como derivaciones finales, comento que el sistema electoral ha pasado por una coyuntura larga que ha definido en buena medida las reglas, y ahora pasa por cambios que no tienen perspectiva a largo plazo. En virtud de lo anterior, la reforma electoral actual está incompleta y la sociedad necesita introducir su agenda, no necesariamente compartida por los partidos políticos.

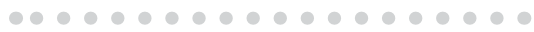

$\begin{array}{lllllllllll} & \mathrm{S} & \mathrm{S} & \mathrm{T} & \mathrm{A} & \mathrm{N} & \mathrm{T} & \mathrm{E} & \mathrm{R} & \mathrm{I} & \mathrm{A}\end{array}$

\section{La amortajada: Catalina Xuárez la Marcaida, Nueva España 1522}

Gladys Ilarregui

A continuación presentamos un fragmento del libro Las mujeres de la Conquista antes y después de Cortés, el cual aparecerá próximamente bajo el sello de Fomento Editorial de la BUAP. La autora argentina radicada en Estados Unidos, analiza las relaciones entre mujeres de los dos mundos, así como su "empoderamiento" en el encuentro o el choque que representó la Conquista bajo la férula del poder patriarcal y la importancia de todos estos elementos en el origen y el desarrollo de la nación mexicana.

Posiblemente Hernán Cortés sea la figura más intrigante de la Conquista por hallarse sumergido en forma histórica en una cantidad de documentos que son casi tan oceánicos como el mar que cruzó para llegar primero al Caribe y luego como líder de la expedición en México. Además de las cinco Cartas de relación que se han hecho famosas, el mundo documental que lo contiene en forma directa -a través de su propia escritura o por dictado- incluye instrucciones, ordenanzas, probanzas, demandas, acusaciones, recibos, contratos, documentos sucesorios, cédulas, provisiones, cartas reales y nombramientos. Una documentación casi tan desbordante como la riqueza material que dejó tras su muerte, que ante los escribanos reluce en las páginas del inventario de sus bienes, en donde todo lo que lo rodea en la Villa de Cuernavaca es de una calidad insuperable para la época. ${ }^{11}$ Su repostero Francisco de Tordesillas, va guiando a los escribanos en el repaso de los platos, jarros, tazas y candeleros de plata que junto a una cruz dorada hecha por los indios y cerca de un hostiario de plata quintado, vaciadizo, que pesa tres marcos, recuerdan la contradicción auténtica de una vida 